\title{
MODIFICAÇÕES NA COMPOSIÇÃO QUÍMICA E PADRÃO DE FERMENTAÇÃO EM SILAGENS DE SEIS HÍBRIDOS DE MILHO
}

\author{
ROBERTO CAMARGOS ANTUNES ${ }^{1}$, RONALDO BRAGA REIS ${ }^{2}$, LÚCIO CARLOS GONÇALVES ${ }^{2}$, \\ JOSÉ AVELINO SANTOS RODRIGUES ${ }^{3}$, NORBERTO MARIO RODRIGUEZ ${ }^{2}$, ANA LUIZA COSTA \\ CRUZ BORGES ${ }^{2}$ e IRAN BORGES ${ }^{2}$
}

${ }^{1}$ SGAN 914, Conjunto H, Bloco B, Apartamento № 208. Asa Norte, Brasília, Distrito Federal. CEP: 70.790-140. Email:camargos@cnpq.br

${ }^{2}$ Departamento de Zootecnia da Escola de Veterinária da UFMG. Avenida Antônio Carlos, 6627, Campus Pampulha, Belo Horizonte/MG. CEP: 30.123-970. E-mail: luciocg@vet.ufmg.br

${ }^{3}$ Embrapa Milho e Sorgo, Rodovia MG 424, km 45, Sete Lagoas/MG. CEP 35701-970. E-mail: avelino@cnpms.embrapa.br

Revista Brasileira de Milho e Sorgo, v.5, n.3, p.422-430, 2006

RESUMO - Empresas de melhoramento genético vegetal lançam vários híbridos de milho no mercado todos os anos. Grande parte desses híbridos é utilizada para a produção de silagem. Dessa forma, esse trabalho objetivou estudar as principais modificações da composição química e o padrão de fermentação das silagens produzidas por seis híbridos de milho (HD 9481, P 3041, C 435, HT 951005, HT 47C e AG 5011). As plantas inteiras do milho foram ensiladas no estádio de maturidade fisiológica (3/4 de "linha do leite"), em silos laboratoriais de PVC, com $10 \mathrm{~cm}$ de diâmetro. A forragem foi avaliada com 0 (zero), 1, 3, 5, 7, 14, 28 e 56 dias após a ensilagem. Foram analisados os teores de matéria seca (MS), de carboidratos solúveis (CS), de fibra detergente neutro (FDN), de proteína bruta (PB), de nitrogênio amoniacal e o pH. Os teores médios de MS nas silagens variaram de 34,51 a $42,90 \%$. A maior parte dos CS foi consumida até o $5^{\circ}$ dia da fermentação. Os teores de PB e de FDN permaneceram praticamente estáveis durante a ensilagem. Os valores de $\mathrm{pH}$ se estabilizaram a partir do $5^{\circ}$ dia da fermentação, para a maioria dos híbridos, e foram sempre menores que 3,82 no $56^{\circ}$ dia. Os teores de nitrogênio amoniacal, embora não tenham se estabilizado até o $56^{\circ}$ dia da ensilagem, foram sempre menores que $10 \%$. As silagens foram classificadas como de boa qualidade.

Palavras-chave: carboidratos solúveis, nitrogênio amoniacal, qualidade de silagens, silos laboratoriais

\section{CHANGES ON CHEMICAL COMPOSITION AND FERMENTATION PATTERN OF SIX CORN HYBRIDS SILAGES}

\begin{abstract}
Every year, genetic improvement companies introduce several corn hybrids in the market. A great number of those hybrids is used for silage production. Thus, this work was undertaken to study the main changes on chemical composition and fermentation pattern of silages produced with six corn hybrids (HD 9481, P 3041, C 435, HT 951005, HT 47C and AG 5011). Whole corn plants were ensiled at physiologic maturity (3/4 "milk line") in laboratory silos (10 cm diameter). Forage was evaluated at 0 (zero), 1, 3, 5, 7, 14, 28, and 56 days after ensiling. Analyses were made for dry matter
\end{abstract}


(DM), soluble carbohydrates (SC), neutral detergent fiber (NDF), crude protein (CP), ammonium nitrogen, and $\mathrm{pH}$. The dry matter contents in silages varied from 34.51 to $42.90 \%$. The greatest part of SC was utilized until the $5^{\text {th }}$ day of fermentation. Neutral detergent fiber and crude protein fractions remained practically constant during ensilage. All $\mathrm{pH}$ values were lower than 3.82 and tended to stability after the $5^{\text {th }}$ day of fermentation. Ammonia nitrogen levels were lower than $10 \%$, but did not stabilize until the $56^{\text {th }}$ day of fermentation. All silages were classified as good quality.

Key words: soluble carbohydrates, ammonium nitrogen, silage quality, laboratory silos

No Brasil, a maior parte do rebanho bovino é criada em condições extensivas, em pasto, durante todo o ano. Embora, pequena, porém crescente parcela de produtores adota a prática de produção de silagens como estratégia de suplementação volumosa na época seca do ano.

A ensilagem, apesar de ser uma forma eficiente de conservação de volumosos úmidos, provoca modificações na composição química da forragem (McDonald et al., 1991), sendo bem descritos o consumo pelos microrganismos dos carboidratos solúveis (CS) e de parte da hemicelulose (McAllan \& Phipps, 1977), a proteólise e degradação de aminoácidos (Jones et al., 1992) e o aumento proporcional da fração menos digestível da parede celular. Essas modificações culminam na redução do valor nutritivo da forragem ensilada em relação à forragem original (Doane et al., 1996).

Híbridos e variedades de milho são lançados no mercado todos os anos (Aseltine, 1988). Esses podem possuir características agronômicas mais adequadas (maior produtividade de MS, maior resistência ao alumínio do solo e outras) ou composições químicas diferenciadas (maiores teores de PB na forragem e de óleo nos grãos e menores teores de lignina). Grande parte desses novos materiais genéticos é utilizada por produtores para a produção de silagem. Espera-se que eles propiciem a produção de silagens de alta qualidade nutritiva para ruminantes e que pos- sam contribuir positivamente para a produtividade animal.

Este trabalho objetivou estudar as principais modificações da composição química e o padrão de fermentação das silagens produzidas por seis híbridos de milho (HD 9481, P 3041, C 435, HT 951005, HT 47C e AG 5011), em condições laboratoriais.

\section{Material e Métodos}

Seis híbridos de milho (HD 9481, HT 47C, HT 951005, AG 5011, C 435 e P 3041) foram cultivados em área da Embrapa Milho e Sorgo, em Sete Lagoas, MG, utilizando capina manual e irrigação por aspersão. O milho foi colhido para a produção de silagem quando os grãos encontravam-se no estádio de maturação fisiológica (3/4 da "linha do leite"). As plantas inteiras foram picadas, em picadeira estacionária, em partículas de aproximadamente $1 \mathrm{~cm}$. O material picado foi homogeneizado e imediatamente ensilado em silos laboratoriais de PVC, com $10 \mathrm{~cm}$ de diâmetro e $40 \mathrm{~cm}$ de altura, dotados de válvula do tipo Bunsen, para o escape de gases. Parte do material picado foi amostrada e analisada como o material original (MO) do experimento.

Os silos laboratoriais permaneceram à temperatura ambiente até o dia de abertura. As avaliações ocorreram com 0 (zero), 1, 3, 5, 7, 14, 28 e 56 dias após a ensilagem. As silagens foram removidas dos silos e homogeneizadas e as amos- 
tras foram secadas em estufa de ventilação forçada a $65^{\circ} \mathrm{C}$, por 72 horas (AOAC, 1980), e moídas em moinho tipo Willey, dotado de peneira de malha de $1 \mathrm{~mm}$.

Nos materiais pré-secados e moídos, foram determinados os teores de $\mathrm{MS}$ a $105^{\circ} \mathrm{C}$, de PB (AOAC, 1980), de CS em etanol a 80\% (Bailey, 1967, adaptada por Valadares Filho, 1981) e de FDN (Van Soest et al., 1991). Para a análise dos teores de fibra em detergente neutro - FDN, foram utilizados $50 \mathrm{ml}$ de amilase termoestável adicionada ao início da fervura (Termamyl 120 L a 1\%, Novo Nordisk Bioindustrial do Brasil). Os valores de $\mathrm{pH}$ e os teores de nitrogênio amoniacal, expressos como porcentagem de nitrogênio amoniacal sobre o nitrogênio total na base da matéria seca (N-NH3/NT, em \%), foram determinados nos sucos das silagens, obtidos por meio de prensagem.

O delineamento estatístico foi o inteiramente casualisado, em esquema fatorial 6 x 8, com duas repetições. Os tratamentos foram os seis híbridos de milho e as oito épocas de abertura dos silos (incluindo-se o dia zero). Os dados foram submetidos à análise de variância e as médias foram comparadas pelo teste SNK, ao nível de significância de 5,0\%, utilizando o SAEG (1999).

\section{Resultados e Discussão}

Os teores de MS do material original (dia zero) e das silagens são apresentados na Tabela 1. Houve diferenças nos teores de MS entre os híbridos, em todos os dias de abertura dos silos. O híbrido P 3041 apresentou os maiores teores de MS no material original e nas silagens no $3^{\circ}$, $5^{\circ}$ e $7^{\circ}$ dias após a ensilagem, sempre acima de 40\%. Os híbridos HT 951005 e C 435 apresentaram teores de $\mathrm{MS}$ menores que $36 \%$. Os teores de matéria seca dos híbridos HD 9481, HT 47C, AG 5011 e P 3041 foram superiores a 35\% em todos os tempos de abertura, nível convencionalmente aceito como limite superior de matéria seca para a produção de silagens de milho de boa qualidade (Ferreira, 1991; Valente, 1991). Porém, Danley \& Vetter (1973) produziram silagem de milho de boa qualidade com teores de matéria seca entre 30,4 e 41\%. Maia (2001) também produziu silagens de milho de boa qualidade com 34,1 a 39,0\% de matéria seca. Os teores de matéria seca no $56^{\circ}$ dia não foram diferentes do material original para cinco dos seis híbridos, com exceção do híbrido P3041, para o qual houve redução no teor de MS.

Houve diferenças entre híbridos quanto aos teores de carboidratos solúveis (CS) no ma-

TABELA 1. Concentrações de matéria seca do material original (dia zero) e das silagens de seis genótipos de milho, expressas em porcentagem ${ }^{1}$

\begin{tabular}{lllllllll}
\hline \multirow{2}{*}{ Genótipo } & \multicolumn{7}{c}{ Dias após a ensilagem } \\
\cline { 2 - 8 } & \multicolumn{1}{c}{$\mathbf{0}$} & \multicolumn{1}{c}{$\mathbf{1}$} & $\mathbf{3}$ & \multicolumn{1}{c}{$\mathbf{5}$} & \multicolumn{1}{c}{$\mathbf{1 4}$} & \multicolumn{1}{c}{$\mathbf{2 8}$} & $\mathbf{5 6}$ \\
\hline HD 9481 & $40,7 \mathrm{Ba}$ & $40,0 \mathrm{Aa}$ & $40,2 \mathrm{Ba}$ & $38,0 \mathrm{Ba}$ & $38,1 \mathrm{Ca}$ & $39,8 \mathrm{Aa}$ & $39,3 \mathrm{Ba}$ & $39,5 \mathrm{ABa}$ \\
HT 47C & $40,2 \mathrm{Bab}$ & $40,5 \mathrm{Aab}$ & $41,9 \mathrm{Ba}$ & $40,0 \mathrm{Bab}$ & $41,3 \mathrm{Bab}$ & $40,8 \mathrm{Aab}$ & $40,6 \mathrm{ABab}$ & $38,7 \mathrm{ABb}$ \\
HT 951005 & $34,5 \mathrm{Cab}$ & $34,2 \mathrm{Bab}$ & $34,3 \mathrm{Cab}$ & $35,2 \mathrm{Cab}$ & $35,9 \mathrm{Da}$ & $34,7 \mathrm{Bab}$ & $34,0 \mathrm{Cab}$ & $32,9 \mathrm{Cb}$ \\
AG 5011 & $40,5 \mathrm{Bab}$ & $40,6 \mathrm{Aab}$ & $41,5 \mathrm{Ba}$ & $39,7 \mathrm{Bab}$ & $41,3 \mathrm{Bab}$ & $40,6 \mathrm{Aab}$ & $39,7 \mathrm{ABab}$ & $38,0 \mathrm{Bb}$ \\
C 435 & $35,0 \mathrm{Ca}$ & $35,6 \mathrm{Ba}$ & $36,0 \mathrm{Ca}$ & $34,8 \mathrm{Ca}$ & $35,3 \mathrm{Da}$ & $35,0 \mathrm{Ba}$ & $34,3 \mathrm{Ca}$ & $33,3 \mathrm{Ca}$ \\
P 3041 & $44,6 \mathrm{Aa}$ & $41,8 \mathrm{Ab}$ & $45,3 \mathrm{Aa}$ & $42,6 \mathrm{Ab}$ & $44,9 \mathrm{Aa}$ & $40,9 \mathrm{Ab}$ & $41,9 \mathrm{Ab}$ & $40,9 \mathrm{Ab}$ \\
\hline
\end{tabular}

${ }^{1}$ Valores seguidos por letras maiúsculas iguais, na mesma coluna, e por letras minúsculas iguais, na mesma linha, não diferem estatisticamente $(\mathrm{P}>0,05)$ pelo teste $\mathrm{SNK}$. $\mathrm{CV}=2,44 \%$. 
terial original (MO) (Tabela 2). O híbrido C 435 apresentou o maior teor $(12,71 \%)$, enquanto os híbridos AG 5011 e P 3041 apresentaram os menores teores de CS (4,81 e 5,46\%, respectivamente). Os demais híbridos apresentaram valores entre 6,45 e 7,53\% de CS. Os teores de CS foram semelhantes aos encontrados por Maia (2001) para silagens de milho $(4,0$ a 9,2\%). Teores maiores de CS na forragem do milho foram encontrados por Rodrigues et al. (2004), de 9,8\% aos 97 dias pós-plantio, no estádio farináceo duro.

A redução dos teores de CS foi intensa, sendo quase completamente consumidos até o $3^{\circ}$ dia da fermentação. $\mathrm{O}$ consumo pelos microrga- nismos de CS cessou no $1^{\circ}$ dia de fermentação para o híbrido AG 5011, no $3^{\circ}$ dia, para os híbridos HD 9481, HT 47C, HT 951005 e P 3041, e no $5^{\circ}$ dia, para o $\mathrm{C} 435$. A partir do $5^{\circ}$ dia, não houve diferença nos teores de CS entre híbridos. Jonhson et al. (2003) relataram que os CS nas silagens de milho foram quase completamente reduzidos dentro dos três primeiros dias de ensilagem, com intensa formação de ácido lático, o que explicou, em grande parte, a rápida queda do $\mathrm{pH}$ da massa ensilada.

Houve diferença nos valores de $\mathrm{pH}$ entre híbridos para todos os dias de abertura dos silos, com exceção para o $28^{\circ}$ dia (Tabela 3 ). Os valo-

TABELA 2. Concentrações de carboidratos solúveis em etanol a $80 \%$ do material original (dia zero) e das silagens de seis genótipos de milho, em porcentagem da matéria seca ${ }^{1}$

\begin{tabular}{lllcccccc}
\hline \multirow{2}{*}{ Genótipo } & \multicolumn{7}{c}{$\mathbf{8}$ Dias após a ensilagem } \\
\cline { 2 - 8 } & \multicolumn{1}{c}{$\mathbf{1}$} & $\mathbf{3}$ & $\mathbf{5}$ & $\mathbf{7}$ & $\mathbf{1 4}$ & $\mathbf{2 8}$ & $\mathbf{5 6}$ \\
\hline HD 9481 & $6,4 \mathrm{Ca}$ & $3,6 \mathrm{Db}$ & $1,0 \mathrm{Bc}$ & $0,7 \mathrm{Ac}$ & $0,6 \mathrm{Ac}$ & $0,8 \mathrm{Ac}$ & $0,7 \mathrm{Ac}$ & $1,0 \mathrm{Ac}$ \\
HT 47C & $7,5 \mathrm{Ba}$ & $4,8 \mathrm{Cb}$ & $1,0 \mathrm{Bc}$ & $0,8 \mathrm{Ac}$ & $0,8 \mathrm{Ac}$ & $0,9 \mathrm{Ac}$ & $0,9 \mathrm{Ac}$ & $1,2 \mathrm{Ac}$ \\
HT 951005 & $6,0 \mathrm{CDa}$ & $5,8 \mathrm{Ba}$ & $1,4 \mathrm{Bb}$ & $1,1 \mathrm{Ab}$ & $1,0 \mathrm{Ab}$ & $1,1 \mathrm{Ab}$ & $1,3 \mathrm{Ab}$ & $1,3 \mathrm{Ab}$ \\
AG 5011 & $4,8 \mathrm{Ea}$ & $1,9 \mathrm{~Eb}$ & $0,9 \mathrm{Bb}$ & $1,0 \mathrm{Ab}$ & $1,0 \mathrm{Ab}$ & $1,0 \mathrm{Ab}$ & $0,9 \mathrm{Ab}$ & $1,5 \mathrm{Ab}$ \\
C 435 & $12,7 \mathrm{Aa}$ & $11,5 \mathrm{Ab}$ & $2,8 \mathrm{Ac}$ & $1,3 \mathrm{Ad}$ & $1,4 \mathrm{Ad}$ & $1,5 \mathrm{Ad}$ & $1,4 \mathrm{Ad}$ & $1,4 \mathrm{Ad}$ \\
P 3041 & $5,4 \mathrm{DEa}$ & $3,1 \mathrm{Db}$ & $0,9 \mathrm{Bc}$ & $0,9 \mathrm{Ac}$ & $0,7 \mathrm{Ac}$ & $0,8 \mathrm{Ac}$ & $0,9 \mathrm{Ac}$ & $1,2 \mathrm{Ac}$ \\
\hline
\end{tabular}

${ }^{1}$ Valores seguidos por letras maiúsculas iguais, na mesma coluna, e por letras minúsculas iguais, na mesma linha, não diferem estatisticamente $(\mathrm{P}>0,05)$ pelo teste $\mathrm{SNK}$. CV $=16,90 \%$

TABELA 3. Valores de $\mathrm{pH}$ dos sucos das silagens de seis genótipos de milho, com o avanço da fermentação ${ }^{1}$

\begin{tabular}{lcclcccc}
\hline \multirow{2}{*}{ Genótipo } & \multicolumn{7}{c}{ Dias após a ensilagem } \\
\cline { 2 - 7 } & $\mathbf{1}$ & $\mathbf{3}$ & $\mathbf{5}$ & $\mathbf{7}$ & $\mathbf{1 4}$ & $\mathbf{2 8}$ & $\mathbf{5 6}$ \\
\hline HD 9481 & $4,8 \mathrm{BCa}$ & $4,0 \mathrm{Bb}$ & $3,8 \mathrm{BCc}$ & $3,8 \mathrm{Bc}$ & $3,7 \mathrm{ABc}$ & $3,8 \mathrm{Ac}$ & $3,7 \mathrm{ABc}$ \\
HT 47C & $4,8 \mathrm{BCa}$ & $4,0 \mathrm{Bb}$ & $3,7 \mathrm{CDc}$ & $3,8 \mathrm{Bc}$ & $3,8 \mathrm{ABc}$ & $3,8 \mathrm{Ac}$ & $3,7 \mathrm{ABc}$ \\
HT 951005 & $4,7 \mathrm{Ca}$ & $4,0 \mathrm{Bb}$ & $3,7 \mathrm{Dc}$ & $3,8 \mathrm{Bc}$ & $3,8 \mathrm{ABc}$ & $3,8 \mathrm{Ac}$ & $3,7 \mathrm{ABc}$ \\
AG 5011 & $4,9 \mathrm{Ba}$ & $4,3 \mathrm{Ab}$ & $3,7 \mathrm{ABc}$ & $4,0 \mathrm{Ac}$ & $3,9 \mathrm{Acd}$ & $3,9 \mathrm{Acd}$ & $3,8 \mathrm{ABd}$ \\
C 435 & $4,9 \mathrm{Ba}$ & $3,9 \mathrm{Bb}$ & $3,5 \mathrm{Dc}$ & $3,7 \mathrm{Bc}$ & $3,7 \mathrm{Bc}$ & $3,7 \mathrm{Ac}$ & $3,6 \mathrm{Bc}$ \\
P 3041 & $5,1 \mathrm{Aa}$ & $4,3 \mathrm{Ab}$ & $4,2 \mathrm{Ac}$ & $4,0 \mathrm{Ac}$ & $3,9 \mathrm{Acd}$ & $3,9 \mathrm{Acd}$ & $3,8 \mathrm{Ad}$ \\
\hline
\end{tabular}

${ }^{1}$ Valores seguidos por letras maiúsculas iguais, na mesma coluna, e por letras minúsculas iguais, na mesma linha, não diferem estatisticamente $(\mathrm{P}>0,05)$ pelo teste $\mathrm{SNK} . \mathrm{CV}=1,37 \%$ 
res de $\mathrm{pH}$ das silagens no $56^{\circ}$ dia foram semelhantes aos encontrados por Moraes Genro et al. (1995) e por Maia (2001), que obtiveram valores de 3,5 a 3,6 e de 3,68 a 3,79, respectivamente, para silagens de milho. Os valores de $\mathrm{pH}$ diminuíram rapidamente nos três primeiros dias de ensilagem e estabilizaram a partir do $5^{\circ}$ dia, para quatro híbridos (HD 9481, HT 47C, HT 951005 e C 435). Esses resultados foram semelhantes aos encontrados por Jonhson et al. (2003), em que o $\mathrm{pH}$ das silagens de milho estabilizou-se a partir do sexto dia da fermentação. $\mathrm{O}$ pH abaixou no $14^{\circ}$ dia, para os híbridos AG 5011 e P 3041, mostrando que a fermentação continuou ativa mais tempo durante a ensilagem. Os carboidratos solúveis são a fonte de energia prontamente disponível para as bactérias ácido-láticas, que sintetizam o ácido lático como produto final do seu metabolismo anaeróbico, desde que as condições de anaerobiose sejam rapidamente atingidas no silo (Muck, 1988). A síntese e o acúmulo de ácido lático na silagem são os responsáveis pela rápida queda do $\mathrm{pH}$, o principal mecanismo de conservação da forragem ensilada (McDonald et al., 1991).

Não houve diferença nos teores de FDN entre híbridos nos $1^{\circ}, 3^{\circ}, 5^{\circ}$ e $56^{\circ}$ dias após a ensilagem (Tabela 4). Os valores de FDN desse experimento foram semelhantes aos encontrados por Melo et al. (1999), 54,04\%, e maiores que os encontrados por Kuehn et al. (1999), que variaram de 43,6 a 45,6\%, para silagens de híbridos de milho granífero e forrageiro, respectivamente. Os teores de FDN de quatro dos seis híbridos não variaram com o avanço da fermentação. Houve redução apenas para os híbridos HD 9481 e AG 5011, no 56 dia, em relação ao MO. Para os demais híbridos, não houve alteração nos teores de FDN com o avanço do período de ensilagem. A redução da FDN pode ocorrer durante a ensilagem devido à solubilização da hemicelulose pelos microrganismos hemicelulolíticos. Esse polissacarídeo complexo da parede celular é uma fonte secundária de carboidratos fermentecíveis durante a ensilagem (McDonald et al., 1991). A redução dos teores de FDN com a ensilagem pode, teoricamente, favorecer a ingestão da silagem, pois o teor de FDN do volumoso é negativamente correlacionado com a ingestão por ruminantes (Sudweeks et al., 1981; Mertens, 1997).

Houve diferenças no teor de PB entre híbridos durante todo o período de avaliação (Tabela 5). O híbrido AG 5011 destacou-se com o maior teor de PB, com média de $8,64 \%$. Os teores de $\mathrm{PB}$ foram semelhantes aos encontrados por Melo et al., (1999), que relataram valores

TABELA 4. Concentrações de fibra detergente neutro do material original (dia zero) e das silagens de seis genótipos de milho, em porcentagem da matéria seca ${ }^{1}$

\begin{tabular}{|c|c|c|c|c|c|c|c|c|}
\hline \multirow{2}{*}{ Genótipo } & \multicolumn{8}{|c|}{ Dias após a ensilagem } \\
\hline & $\mathbf{0}$ & 1 & 3 & 5 & 7 & 14 & 28 & 56 \\
\hline HD 9481 & $59,6 \mathrm{Aa}$ & $57,7 \mathrm{Aab}$ & $53,4 \mathrm{Aab}$ & $55,2 \mathrm{Aab}$ & $54,4 \mathrm{ABab}$ & $52,7 \mathrm{ABab}$ & $54,2 \mathrm{ABab}$ & $51,4 \mathrm{Ab}$ \\
\hline HT 47C & $57,5 \mathrm{ABab}$ & $59,9 \mathrm{Aa}$ & $55,0 \mathrm{Aab}$ & $53,7 \mathrm{Aab}$ & $51,7 \mathrm{ABb}$ & $58,1 \mathrm{Aab}$ & $54,4 \mathrm{ABab}$ & $53,6 \mathrm{Aab}$ \\
\hline HT 951005 & $58,0 \mathrm{ABa}$ & $56,1 \mathrm{Aab}$ & 56,9Aabc & $50,0 \mathrm{Abc}$ & $51,7 \mathrm{ABabc}$ & $50,6 \mathrm{Babc}$ & $47,7 \mathrm{Bc}$ & $51,0 \mathrm{Aabc}$ \\
\hline AG 5011 & $61,1 \mathrm{Aa}$ & $59,3 \mathrm{Aab}$ & $58,2 \mathrm{Aabc}$ & $54,0 \mathrm{Aabc}$ & $54,4 \mathrm{ABabc}$ & $58,6 \mathrm{Aab}$ & $51,1 \mathrm{Ac}$ & $53,0 \mathrm{Abc}$ \\
\hline C 435 & $61,2 \mathrm{Aab}$ & $62,4 \mathrm{Aa}$ & $59,4 \mathrm{Aab}$ & $57,2 \mathrm{Aab}$ & $57,5 \mathrm{Aab}$ & $55,4 \mathrm{ABab}$ & $56,0 \mathrm{Aab}$ & $53,9 \mathrm{Ab}$ \\
\hline P 3041 & $52,2 \mathrm{Bab}$ & $57,8 \mathrm{Aa}$ & $59,6 \mathrm{Aa}$ & $52,8 \mathrm{Aab}$ & $48,6 \mathrm{Bb}$ & $57,6 \mathrm{Aa}$ & $48,6 \mathrm{Bb}$ & $53,0 \mathrm{Aab}$ \\
\hline
\end{tabular}

${ }^{1}$ Valores seguidos por letras maiúsculas iguais, na mesma coluna, e por letras minúsculas iguais, na mesma linha, não diferem estatisticamente $(\mathrm{P}>0,05)$ pelo teste $\mathrm{SNK}$. CV $=4,51 \%$ 
médios de PB para 30 cultivares de milho de $7,85 \%$, e aos de Maia (2001), que encontrou valores de 6,9 a $8,4 \%$.

Os teores de PB permaneceram constantes durante o processo fermentativo, para a maioria das silagens. É bem conhecido que os teores de PB permanecem estáveis durante a ensilagem (McDonald et al., 1991). Porém, o perfil bioquímico da $\mathrm{PB}$ muda radicalmente, devido à intensa proteólise promovida pelas proteases da própria forragem e dos microrganismos no silo, nos primeiros dias. Na forragem fresca, cerca de $75 \%$ a $90 \%$ da PB é formada por proteína verdadeira (Ohshima \& McDonald, 1978). Já na silagem, somente cerca de $20 \%$ da PB encontra-se na forma de proteína verdadeira, sendo o restante (até $80 \%$ da PB) composto por nitrogênio não protéico (McDonald et al., 1991). Essa intensa modificação da fração protéica torna a PB da silagem mais solúvel e mais rapidamente disponível para o metabolismo microbiano ruminal. Isso pode ocasionar falta de sincronia na relação energia: proteína no rúmen, prejudicando a eficiência de síntese de proteína microbiana (Harrison et al., 1994). A baixa qualidade da PB das silagens naturalmente fermentadas tem sido considerada como um fator ne- gativo sobre o desempenho de vacas de alta produção, pois há a necessidade de utilização de maiores quantidades de fontes de proteínas mais lentamente degradáveis no rúmen, o que incorre em aumento dos custos (Muck, 1988).

$\mathrm{Na}$ Tabela 6, são demonstradas as porcentagens de nitrogênio amoniacal em relação ao nitrogênio total (N-NH3/NT) nas silagens. Não houve diferenças nesse aspecto entre os híbridos até o $7^{\circ}$ dia de ensilagem. No $56^{\circ}$ dia de ensilagem, o híbrido AG 5011 apresentou maior teor de N-NH3/NT que o HD 9481 e C 435 (6,89, 5,79 e $5,60 \%$, respectivamente). Os teores de $\mathrm{N}$ NH3/NT aumentaram linearmente com o avanço da fermentação, para todos os híbridos. Segundo McDonald et al. (1991), a formação de amônia no silo é o resultado da degradação de aminoácidos pelos microrganismos e também por enzimas da forrageira. Porém, os valores encontrados no $56^{\circ}$ dia foram bastante reduzidos, estando abaixo de $10 \%$. Valores semelhantes foram relatados por Maia (2001) para silagens de milho (menores que 5,5\%).

A presença de nitrogênio amoniacal nas silagens se deve, principalmente, à degradação de aminoácidos e de alguns outros compostos nitrogenados não protéicos presentes na forragem,

TABELA 5. Concentrações de proteína bruta do material original (dia zero) e das silagens de seis genótipos de milho, em porcentagem da matéria seca ${ }^{1}$

\begin{tabular}{lllllllll}
\hline \multirow{2}{*}{ Genótipo } & \multicolumn{7}{c}{ Dias após a ensilagem } \\
\cline { 2 - 8 } & \multicolumn{1}{c}{$\mathbf{0}$} & $\mathbf{1}$ & $\mathbf{3}$ & $\mathbf{5}$ & $\mathbf{7}$ & $\mathbf{1 4}$ & $\mathbf{2 8}$ & $\mathbf{5 6}$ \\
\hline HD 9481 & $8,5 \mathrm{ABa}$ & $8,2 \mathrm{Bab}$ & $8,0 \mathrm{Bbc}$ & $7,7 \mathrm{Bc}$ & $7,6 \mathrm{Bc}$ & $7,8 \mathrm{Bc}$ & $7,7 \mathrm{Bc}$ & $7,8 \mathrm{Bc}$ \\
HT 47C & $7,8 \mathrm{Ca}$ & $7,3 \mathrm{Cb}$ & $7,3 \mathrm{Cb}$ & $7,5 \mathrm{Bab}$ & $7,6 \mathrm{Bab}$ & $7,1 \mathrm{Cb}$ & $7,3 \mathrm{Bb}$ & $7,3 \mathrm{Cb}$ \\
HT 951005 & $7,9 \mathrm{Ca}$ & $7,6 \mathrm{Ca}$ & $7,5 \mathrm{Ca}$ & $7,6 \mathrm{Ba}$ & $7,5 \mathrm{Ba}$ & $7,6 \mathrm{Ba}$ & $7,7 \mathrm{Ba}$ & $7,7 \mathrm{BCa}$ \\
AG 5011 & $8,7 \mathrm{Aa}$ & $8,7 \mathrm{Aa}$ & $8,6 \mathrm{Aa}$ & $8,6 \mathrm{Aa}$ & $8,6 \mathrm{Aa}$ & $8,1 \mathrm{Ab}$ & $8,5 \mathrm{Aa}$ & $8,9 \mathrm{Aa}$ \\
C 435 & $7,8 \mathrm{Ca}$ & $7,5 \mathrm{Ca}$ & $7,5 \mathrm{Ca}$ & $7,6 \mathrm{Ba}$ & $7,7 \mathrm{Ba}$ & $7,6 \mathrm{Ba}$ & $7,6 \mathrm{Ba}$ & $7,6 \mathrm{BCa}$ \\
P 3041 & $8,3 \mathrm{Ba}$ & $7,7 \mathrm{Cb}$ & $7,2 \mathrm{Cc}$ & $7,5 \mathrm{Bbc}$ & $7,6 \mathrm{Bbc}$ & $7,5 \mathrm{Bbc}$ & $7,4 \mathrm{Bbc}$ & $7,6 \mathrm{BCbc}$ \\
\hline
\end{tabular}

${ }^{1}$ Valores seguidos por letras maiúsculas iguais, na mesma coluna, e por letras minúsculas iguais, na mesma linha, não diferem estatisticamente $(\mathrm{P}>0,05)$ pelo teste $\mathrm{SNK}$. $\mathrm{CV}=2,03 \%$ 
TABELA 6. Concentrações de nitrogênio amoniacal em relação ao nitrogênio total das silagens de seis genótipos de milho, em porcentagem da matéria seca ${ }^{1}$

\begin{tabular}{lcllllll}
\hline \multirow{2}{*}{ Genótipo } & \multicolumn{7}{c}{ Dias após a ensilagem } \\
\cline { 2 - 7 } & $\mathbf{1}$ & $\mathbf{3}$ & $\mathbf{5}$ & \multicolumn{1}{c}{$\mathbf{7}$} & $\mathbf{1 4}$ & $\mathbf{2 8}$ & $\mathbf{5 6}$ \\
\hline HD 9481 & $2,5 \mathrm{Ad}$ & $3,7 \mathrm{Ac}$ & $4,0 \mathrm{Abc}$ & $3,8 \mathrm{Abc}$ & $4,7 \mathrm{Ab}$ & $5,4 \mathrm{Aa}$ & $5,7 \mathrm{Ba}$ \\
HT 47C & $2,4 \mathrm{Ad}$ & $3,0 \mathrm{Acd}$ & $3,5 \mathrm{Ac}$ & $3,6 \mathrm{Ac}$ & $3,6 \mathrm{BCc}$ & $5,3 \mathrm{Ab}$ & $6,1 \mathrm{ABa}$ \\
HT 951005 & $2,5 \mathrm{Ad}$ & $2,9 \mathrm{Acd}$ & $3,4 \mathrm{Acd}$ & $3,7 \mathrm{Acd}$ & $3,4 \mathrm{BCc}$ & $4,6 \mathrm{ABb}$ & $5,8 \mathrm{BCa}$ \\
AG 5011 & $2,7 \mathrm{Ae}$ & $3,1 \mathrm{Ade}$ & $3,7 \mathrm{Acd}$ & $4,0 \mathrm{Acd}$ & $4,2 \mathrm{ABc}$ & $5,5 \mathrm{Ab}$ & $6,8 \mathrm{Aa}$ \\
C 435 & $2,2 \mathrm{Ac}$ & $2,4 \mathrm{Ac}$ & $3,1 \mathrm{Ac}$ & $3,2 \mathrm{Ac}$ & $3,0 \mathrm{Cc}$ & $4,6 \mathrm{ABb}$ & $5,6 \mathrm{Ca}$ \\
P 3041 & $2,7 \mathrm{Ac}$ & $3,1 \mathrm{Ac}$ & $4,1 \mathrm{Abc}$ & $3,6 \mathrm{Ab}$ & $4,2 \mathrm{ABb}$ & $4,3 \mathrm{Bb}$ & $6,7 \mathrm{ABa}$ \\
\hline
\end{tabular}

${ }^{1}$ Valores seguidos por letras maiúsculas iguais, na mesma coluna, e por letras minúsculas iguais, na mesma linha, não diferem estatisticamente $(\mathrm{P}>0,05)$ pelo teste $\mathrm{SNK}$. $\mathrm{CV}=9,56 \%$.

como o nitrato. Os microrganismos do gênero Clostridium são os principais responsáveis pela degradação de aminoácidos (Ohshima et al., 1979). As principais condições que favorecem o crescimento dos clostrídios são o baixo teor de matéria seca e a baixa taxa de queda do $\mathrm{pH}$ da silagem, principalmente nos momentos iniciais da ensilagem (Muck, 1988), o que não foi observado nesse experimento. Nas fermentações dominadas por estes microrganismos são comuns valores de nitrogênio amoniacal superiores a $20 \%$ do nitrogênio total (Ohshima \& McDonald, 1978).

\section{Conclusões}

A fermentação das silagens foi intensa nos primeiros cinco dias, para todos os híbridos, devido ao rápido consumo pelos microrganismos dos carboidratos solúveis, causando a rápida queda do pH e adequada conservação das silagens. Os seis híbridos estudados mostram-se adequados para a produção de silagens de boa qualidade.

\section{Agradecimentos}

À Embrapa Milho e Sorgo e ao Conselho Nacional de Desenvolvimento Científico e Tecnológico - CNPq.

\section{Literatura Citada}

ASELTINE, M.S. Corn silage quality can vary depending on hybrid planted. Feedstuffs, v. 60 , n. 4, p. 13-15, 1988.

ASSOCIATION OF OFFICIAL ANALYTICAL CHEMISTS. Official methods of analysis. 13 ed. Washington, 1980. 1015p.

BAILEY, R.W. Quantitative studies of ruminant digestion loss of ingested plant carbohydrates from the reticule-rumen. New Zealand Journal of Agricultural Research, v. 10, n. 1, p. 15-32, 1967.

DANLEY, M.M.; VETTER, R.L. Changes in carbohydrate and nitrogen fractions and digestibility of forages: maturity and ensiling. Journal of Animal Science, v. 37, n. 4, p. 994999, 1973.

DOANE, P.H.; PELL, A.N.; SCHOFIELD, P.; PITT, R.E. Soluble carbohydrates in silage. In: 1996 CORNELL NUTRITION CONFERENCE FOR FEED MANUFACTURES, 1996, Rochester-NY. Proceedings... Rochester-NY. 1996, p. 115-120.

FERREIRA, J.J. Aspectos importantes para melhor qualidade da silagem de milho e maior efi- 
ciência na sua utilização. In: EMBRAPA MILHO E SORGO. Milho para silagem: tecnologias, sistemas e custo de produção. Sete Lagoas, p. 5968, 1991. (Circular Técnica, 14).

HARRISON， J.H.; BLAUWIEKEL， R.; STOKES, M.R. Fermentation and utilization of grass silage. Journal of Dairy Science, v. 77, n. 10, p. 3209-3235, 1994.

JONES, B.A.; HATFIELD, R.D.; MUCK, R. Effect of fermentation and bacterial inoculation on Lucerne cell wall. Journal of the Science of Food and Agriculture, v. 60, p. 147-153, 1992.

JONHSON, L.M.; HARRISON, J.H.; DAVIDSON, D.; MAHANNA, W.C.; SHINNERS, K. Corn silage management: effects of hybrid, maturity, inoculation, and mechanical processing on fermentation characteristics. Journal of Dairy Science, v.86, n. 1, p. 287-308, 2003.

KUEHN, C.S.; LINN, J.G.; JOHNSON, D.G.; JUNG, H.G.; ENDRES, M.I. Effect of feeding silages from corn hybrids selected for leafiness or grain to lactating dairy cattle. Journal of Dairy Science, v. 82, n. 12, p. 2746-2755, 1999.

MAIA, F.S. Qualidade e padrão de fermentação das silagens de seis cultivares de milho (BR 106, BR 205, HD 9486, AG 1051, C 701, FO01). Belo Horizonte: Escola de Veterinária da UFMG, 2001. 47p. (Dissertação, Mestrado em Zootecnia).

McALLAN, A.B.; PHIPPS, R.H. The effect of sample date and plant density on the carbohydrate content of forage maize and the changes that occur on ensiling. Journal of Agricultural Science, Cambridge, v. 89, p. 589597, 1977.
McDONALD, P.; HENDERSON, A.R.; HERON, S.J.E. The biochemistry of silage. $2^{\mathrm{a}} \mathrm{Ed}$. Marlow: Chalcombe Publications, 1991. 340p.

MELO, W.M.C.; PINHO, R.G.V.; CARVALHO, M.L.M.; PINHO, E.V.R.V. Avaliação de cultivares de milho para a produção de silagem na região de Lavras - MG. Ciência e Agrotecnologia, Lavras, v. 23, n.1, p. 31-39, 1999.

MERTENS, D.R. Creating a system for meeting the fiber requirements of dairy cows. Journal of Dairy Science, v.80, n. 7, p. 1463-1481, 1997.

MORAES GENRO, T.C.; QUADROS, F.L.F.; COELHO, L.G.M.; COELHO FILHO, R.C. Produção e qualidade de silagens de híbridos de milho (Zea mays) e de híbridos de sorgo (Sorghum bicolor). Ciência Rural, v. 25, n. 3, p. 461-464, 1995.

MUCK, R.E. Factors influencing silage quality and their implications for management. Journal of Dairy Science, v. 71, n. 11, p. 2992-3002, 1988.

OHSHIMA, M.; McDONALD, P. A review of the changes in nitrogenous compounds of herbage during ensiling. Journal of the Science of Food and Agriculture, v. 29, p. 497-505, 1978.

OHSHIMA, M.; McDONALD, P.; ACAMOVIC, $T$. Changes during ensilage in the nitrogenous components of fresh and additive treated ryegrass and lucerne. Journal of the Science of Food and Agriculture, v. 30, p. 97-106, 1979.

RODRIGUES, P.H.M.; RUZANTE, J.M.; SENATORE, A.L.; LIMA, F.R.; MELOTTI, L.; MEYER, P.M. Avaliação do uso de inoculantes microbianos sobre a qualidade fermentativa e nutricional da silagem de milho. Revista Brasileira de Zootecnia, v. 33, n. 3, p. 538-545, 2004. 
SISTEMA de análises estatísticas e genéticas SAEG. Viçosa, MG : UFV, 1999. 59p.

SUDWEEKS, E.M.; ELY, O.L.; MERTENS, D.R.; SISK, L.R. Assessing minimum amounts and form of roughage in ruminants diets: roughage value index system. Journal of Animal Science, v. 53, n. 5, p. 1407-1411, 1981.

VALADARES FILHO, S.C. Digestibilidades aparentes e locais de digestão da matéria seca, energia e carboidratos de fenos de soja perene. Belo Horizonte: Escola de Veterinária da UFMG, 1981. 88p. (Dissertação, Mestrado em Zootecnia).
VALENTE, J.O. Introdução: milho para silagem, tecnologias, sistemas e custo de produção. In: EMBRAPA MILHO E SORGO. Milho para silagem: tecnologias, sistemas e custo de produção. Sete Lagoas, p. 5-7, 1991. (Circular Técnica, 14).

VAN SOEST, P.J.; ROBERTSON, J.B.; LEWIS, B.A. Methods for dietary fiber, neutral detergent fiber, and nonstarch polysaccharides in relation to animal nutrition. Journal of Dairy Science, v. 74 , n. 10, p. 3583-3597, 1991. 